\title{
Interaction Suppression Technique For High-Density Antenna Arrays For mm-Wave 5G MIMO Systems
}

\author{
Mohammad Alibakhshikenari ${ }^{1 *}$, Bal S. Virdee ${ }^{2}$, Ayman A. Althuwayb $^{3}$, Francisco Falcone ${ }^{4,5}$, Ernesto Limiti ${ }^{1}$ \\ ${ }^{1}$ Electronic Engineering Department, University of Rome “Tor Vergata”, Via del Politecnico 1, 00133 Rome, Italy \\ ${ }^{2}$ London Metropolitan University, Center for Communications Technology, London N7 8DB, UK \\ ${ }^{3}$ Electrical Engineering Department, Jouf University, Sakaka, Aljouf 72388, Saudi Arabia \\ ${ }^{4}$ Electric, Electronic and Communication Engineering Department, Public University of Navarre, 31006 Pamplona, Spain \\ ${ }^{5}$ Institute of Smart Cities, Public University of Navarre, 31006 Pamplona, Spain \\ *alibakhshikenari@ing.uniroma2.it
}

\begin{abstract}
This paper presents the feasibility study of applying a combination of suppression techniques to improve isolation between the radiation elements in high-density antenna arrays and thereby improve the arrays impedance bandwidth and radiation performance. High isolation between adjacent radiation elements was achieved by embedding a crisscrossed decoupling structure comprising slotted microstrip-lines and locating in the ground-plane under each slot a dielectric ring. The proposed periodic array behaves as artificial magnetic conductor (AMC) surfaces as incident waves in the substrate are fully reflected with a near zero degrees reflection phase. The proposed technique suppresses surface-wave propagation. Proof of concept was verified by applying the technique to a $2 \times 4$ linear array of triangular radiation patches designed to operate between 30-35 GHz. The array was implemented on a standard the Rogers RT 5880 substrate. Dimensions of the array are $40 \times 20 \times 0.8 \mathrm{~mm}^{3}$. Measurement confirm improvement is the array's impedance bandwidth, fractional bandwidth, average isolation, radiation gain, and efficiency by $2 \mathrm{GHz}, 6.15 \%,>10 \mathrm{~dB}, 6.6 \mathrm{dBi}$, and $29 \%$. The array operates across $30-35 \mathrm{GHz}$ with average isolation between its radiation elements better than $23 \mathrm{~dB}$, average gain and efficiency of $12 \mathrm{dBi}$ and $85 \%$, respectively. The technique can be applied to mm-Wave 5G MIMO systems.
\end{abstract}

Index Terms - Antenna array, interaction suppression techniques, decoupling, artificial magnetic conductor (AMC), high isolation, millimeter-waves, 5G systems, multiple-input multiple-output (MIMO) antenna systems.

\section{INTRODUCTION}

The exponential growth in the use of smartphones and live streaming is causing mobile data explosion that is causing spectral congestion in the sub- $6 \mathrm{GHz}$ bands. This has coerced research and development of wireless communications at 28 $\mathrm{GHz}$ and beyond for future $5 \mathrm{G}$ cellular systems. The millimeter-wave (mmWave) band offers abundant bandwidth, which can be used to support multi-Gbps transmission speeds per user. However, path-loss for millimeter-wave communications is high, for example, the path-loss for a $1-\mathrm{km}$ link at $28 \mathrm{GHz}$ is $121 \mathrm{~dB}$, however it is $95 \mathrm{~dB}$ commercial $4 \mathrm{G}$ cellular link at $1.4 \mathrm{GHz}$. In addition, the penetration losses are also high $(>20 \mathrm{~dB})$ at $28 \mathrm{GHz}$ for typical building materials such as concrete and brick. It is therefore essential for high-gain antennas to compensate path-loss and establish reliable communications link between the base-station and cellular system [1-3].

To realize reliable communication in a multipath environment, high transmission rate and shorter latency over the current $4 \mathrm{G}$ system, multiple-input multiple-output (MIMO) antenna system is employed in $5 \mathrm{G}$ communication systems. MIMO uses multiple antennas for transmitting and receiving signal. For miniaturization purposes the MIMO system needs to have a small form factor. This means that antenna array in a MIMO system need to be contained in a limited space resulting in drastically reduced gap between adjacent antenna elements. Unfortunately, this causes strong coupling effects that adversely affect the port isolation, radiation efficiency, as well as deteriorated correlation [4-6]. Therefore, the major challenge is to determine the best compromise between miniaturization and high isolation.

Many techniques have been proposed in literature to reduce mutual coupling between antenna elements. Some approaches to suppress interactions between antennas in an array are based on metamaterials and metasurfaces [6, 7], electromagnetic bandgap (EMBG) [8], and inclusion of parasitic elements [9]. These decoupling structures however can adversely affect the performance of arrays. Orthogonal diversity [10] has also been used to enhance the isolation but its effectiveness is limited to small scale MIMO antennas.

In this paper a combination of suppression approaches are applied in the design of a $2 \times 4$ mmWave antenna array to enhance the isolation between the radiation elements. This is achieved by introducing a decoupling structure between the radiation elements. The periodic metallic array structure behaves as artificial magnetic conductor (AMC) surface by introducing a zero degrees reflection phase shift to incident waves. The proposed methodology is shown to be effective at reducing surface-waves and substrate loss, and thereby improve the array's radiation performance. This is achieved without compromising the antenna's dimensions. The antenna array was designed to operate across $30-35 \mathrm{GHz}$ purely for feasibility study, however its design can be easily translated for application in high-density $5 \mathrm{G}$ mmWave systems at the newly allocated licensed bands at $24 \mathrm{GHz}, 28 \mathrm{GHz}, 37 \mathrm{GHz}$, and 39 $\mathrm{GHz}$. 


\section{II. $2 \times 4$ LINEAR ARRAY ANTENNA STRUCTURE}

The proposed $2 \times 4$ antenna array in Fig. 1(a) consists of eight triangular-shaped patches whose underside is a full ground-plane. The array was fabricated on the Rogers RT5880 lossy substrate with dielectric constant of 2.2, loss-tangent of 0.0009 , and thickness of $0.8 \mathrm{~mm}$. The array has dimensions of $40 \times 20 \times 0.8 \mathrm{~mm}^{3}$. The radiation elements are excited separately through $50 \Omega$ microstrip-line feedline.

The simulation results in Figs. 2 and 3 show the array operates over $31 \mathrm{GHz}$ to $34 \mathrm{GHz}$ for $\mathrm{S}_{11} \leq-10 \mathrm{~dB}$, which is corresponded to a fractional bandwidth of $9.23 \%$. Across this operating band the average transmission-coefficient or isolation

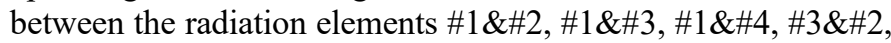
\#3\&\#4, \#3\&\#5, and \#3\&\#6 are $14 \mathrm{~dB}, 13 \mathrm{~dB}, 10 \mathrm{~dB}, 14 \mathrm{~dB}, 17$ $\mathrm{dB}, 15 \mathrm{~dB}$, and $13 \mathrm{~dB}$, respectively. Because the array is symmetrical all other combinations of transmission-coefficient are similar. The minimum, maximum, and average radiation gain and efficiency over its operating band are $5.1 \mathrm{dBi}, 5.8 \mathrm{dBi}$, $5.4 \mathrm{dBi}$, and $51 \%, 62 \%, 56 \%$, respectively.

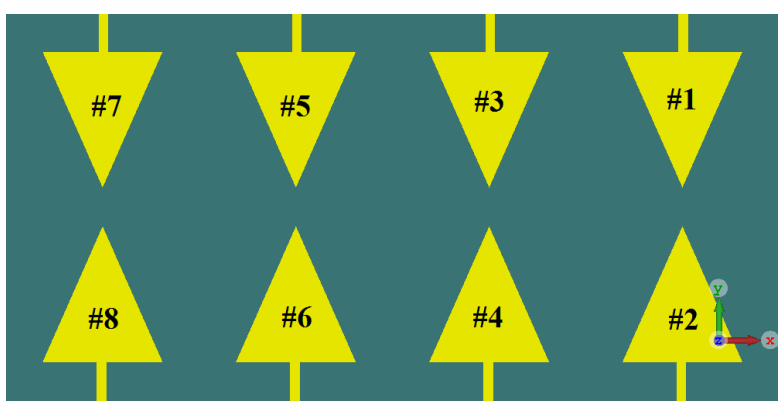

(a)

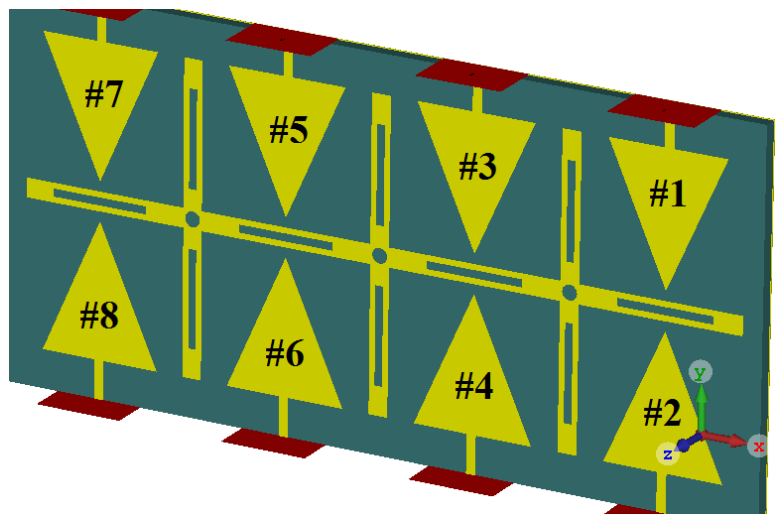

(b)

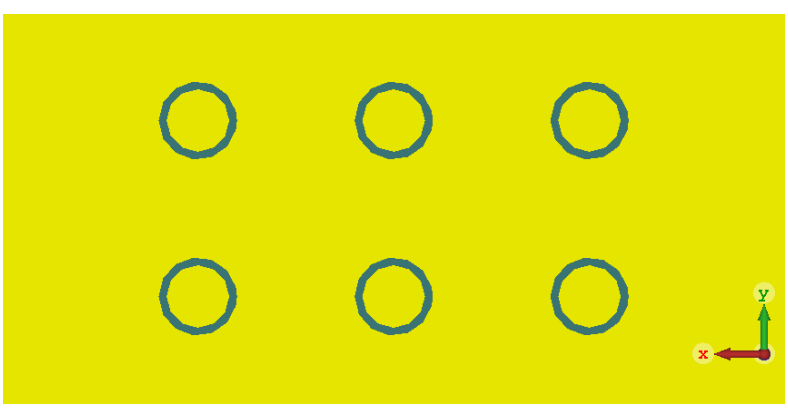

(c)

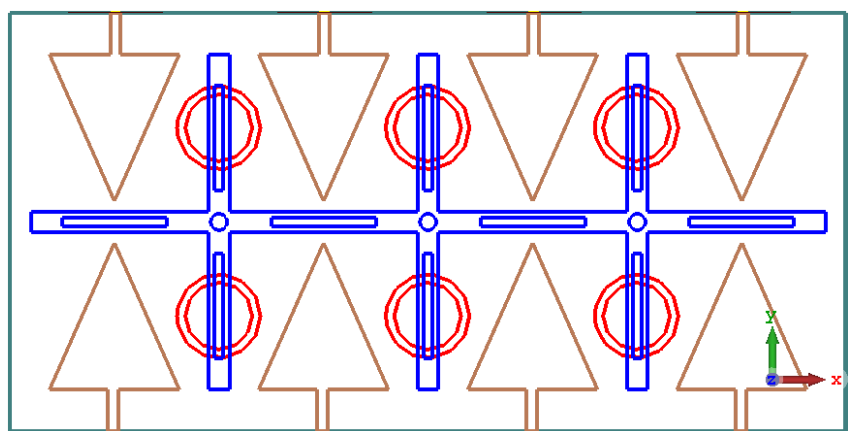

(d)

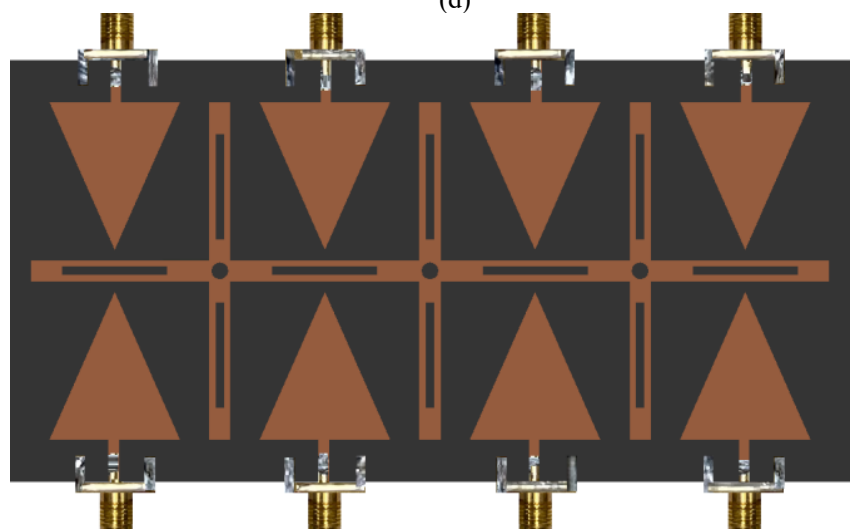

(e)
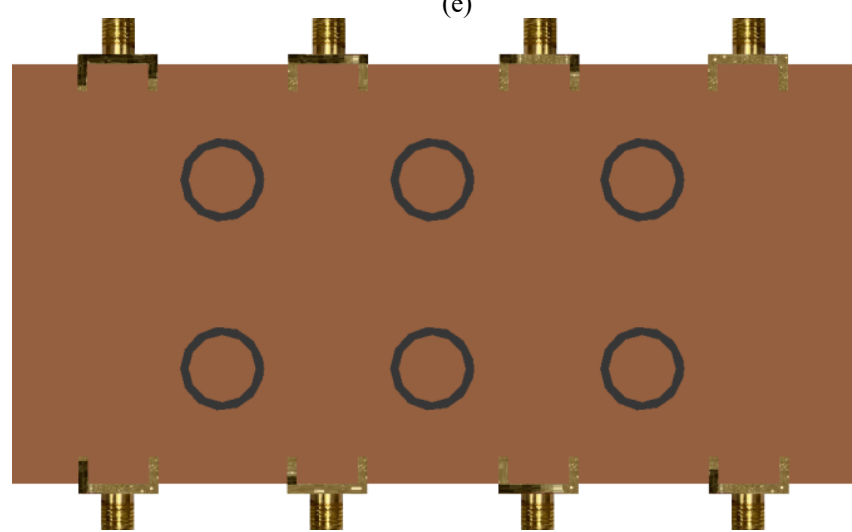

(f)

Fig.1. Configuration of the proposed $2 \times 4$ antenna arrays, (a) standard array, (b) standard array with decoupling structure, (c) ground-plane of "b" with dielectric rings located under the decoupling microstrip-line slots, (d) the overall layout, (e-f) fabricated prototype.

To improve the array antennas radiation characteristics in terms of impedance bandwidth, radiation gain and efficiency we have applied a combination of two techniques to the array without affecting the array's dimensions. This involved embedding a crisscrossed decoupling structure comprising slotted microstrip-lines and located in the ground-plane under each vertical slot is a dielectric ring, as illustrated in Fig. 1(b) \& (c). The periodic metallic array essentially behaves as artificial magnetic conductor surface as incident waves penetrating inside the substrate are fully reflected with a near zero-degree reflection phase. This configuration results in suppressing nearfield electromagnetic interactions between adjacent radiating elements and surface-wave propagation to thereby enhance the radiation characteristics of the array. Fig.1(d) shows a 
schematic view of the proposed array with the decoupling structure and defected ground-plane. The top-view and backview of the fabricated prototype is shown in Fig1.(e) \& (f), respectively. The dimensions of the array are given in Table I.

TABLE I. $2 \times 4$ ARRAY ANTENNASSTRUCTURAL PARAMETERS.

\begin{tabular}{|c|c|}
\hline Antenna array dimensions & $40 \times 20 \times 0.8 \mathrm{~mm}^{3}$ \\
\hline Length of the triangular patches & $6.9 \mathrm{~mm}$ \\
\hline Width of the triangular patches & $6.15 \mathrm{~mm}$ \\
\hline Edge-to-edge gap between the adjacent patches & $3.8 \mathrm{~mm}$ \\
\hline Center-to-center gap between the adjacent patches & $10 \mathrm{~mm}$ \\
\hline Length of the microstrip feedline & $2 \mathrm{~mm}$ \\
\hline Width of the microstrip feedline & $0.5 \mathrm{~mm}$ \\
\hline Length of the horizontal decoupling line & $38 \mathrm{~mm}$ \\
\hline Width of the horizontal decoupling line & $1 \mathrm{~mm}$ \\
\hline Length of the vertical decoupling lines & $16 \mathrm{~mm}$ \\
\hline Width of the vertical decoupling lines & $1 \mathrm{~mm}$ \\
\hline $\begin{array}{c}\text { Length of the rectangular slots etched inside } \\
\text { decoupling structure }\end{array}$ & $5 \mathrm{~mm}$ \\
\hline $\begin{array}{c}\text { Width of the rectangular slots etched inside } \\
\text { decoupling structure }\end{array}$ & $0.4 \mathrm{~mm}$ \\
\hline Radius of slots etched inside decoupling structure & $0.4 \mathrm{~mm}$ \\
\hline Ground-plane (GND) dimensions & $40 \times 20 \times 0.8 \mathrm{~mm}$ \\
\hline Outer radius of dielectric rings etched in the GND & $2 \mathrm{~mm}$ \\
\hline Inner radius of dielectric rings etched in the GND & $1.6 \mathrm{~mm}$ \\
\hline Width of the dielectric rings etched in the GND & $0.4 \mathrm{~mm}$ \\
\hline Center-to-center gap between the dielectric rings & $10 \mathrm{~mm}$ \\
\hline
\end{tabular}

The array's S-parameters were measured to validate its feasibility using a Keysight 8722 ES VNA. Fig. 2 shows the simulated and measured S-parameters of the array without (WO) and with (W). In all cases the array included the decoupling structure and defected ground-plane. With the proposed approach there is improvement in the operating range of $2 \mathrm{GHz}$ from $30-35 \mathrm{GHz}$. This corresponds to a fractional bandwidth of $15.38 \%$, which is an improvement of $6.15 \%$. In addition, the average measured isolation between its radiation

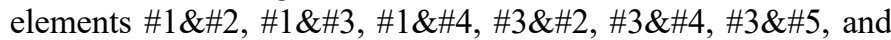
$\# 3 \& \# 6$ are $25 \mathrm{~dB}, 23 \mathrm{~dB}, 23 \mathrm{~dB}, 25 \mathrm{~dB}, 35 \mathrm{~dB}, 30 \mathrm{~dB}$, and 25 $\mathrm{dB}$, respectively. This is an improvement of $11 \mathrm{~dB}, 10 \mathrm{~dB}, 13$ $\mathrm{dB}, 11 \mathrm{~dB}, 18 \mathrm{~dB}, 15 \mathrm{~dB}$, and $12 \mathrm{~dB}$, respectively. The results are summarized in Table II.

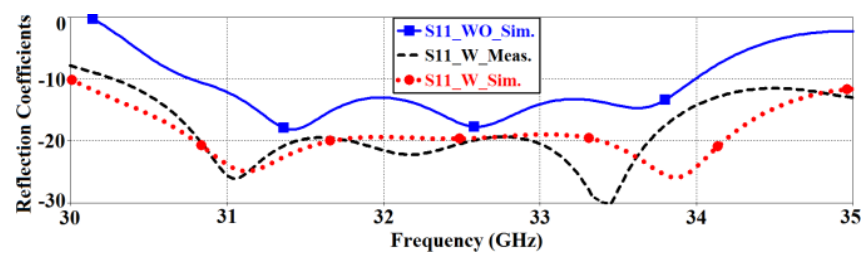

(a)

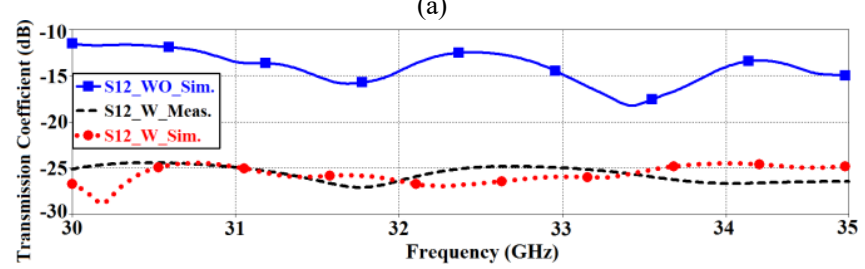

(b)

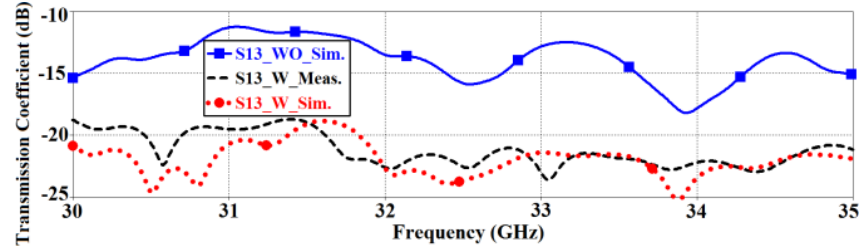

(c)

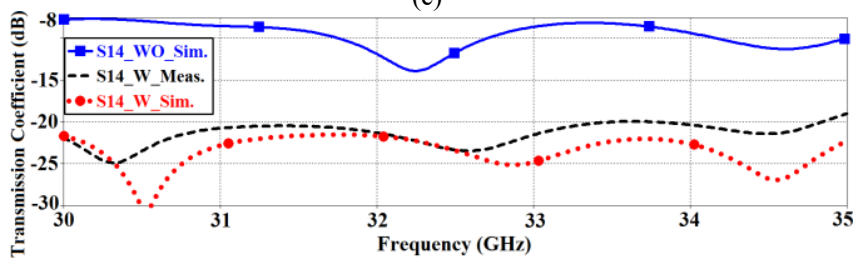

(d)

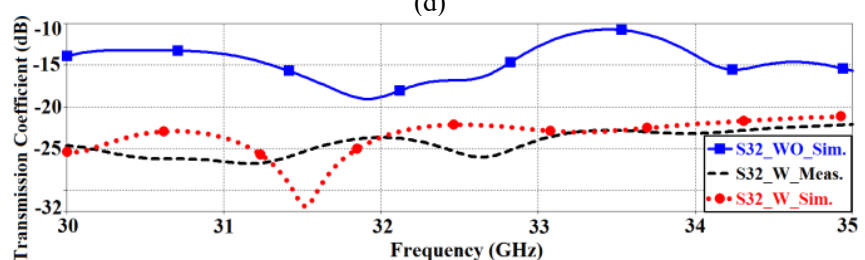

(e)

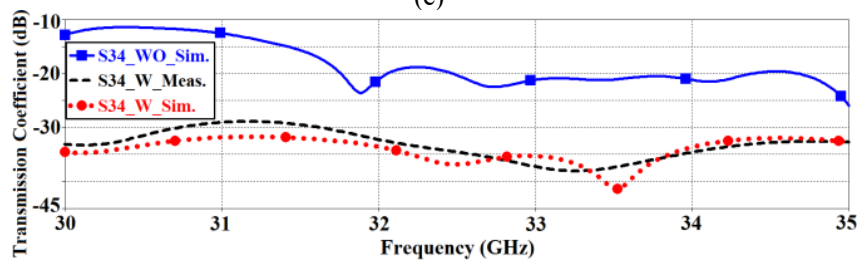

(f)

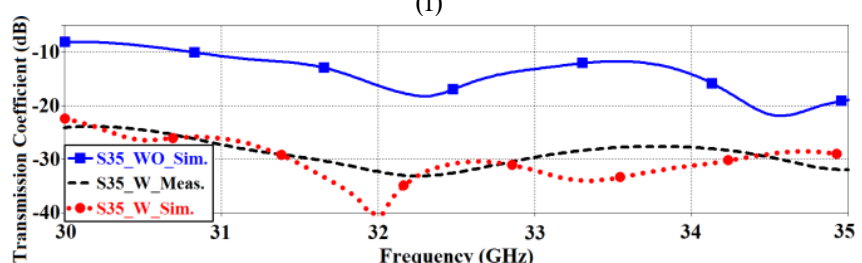

(g)

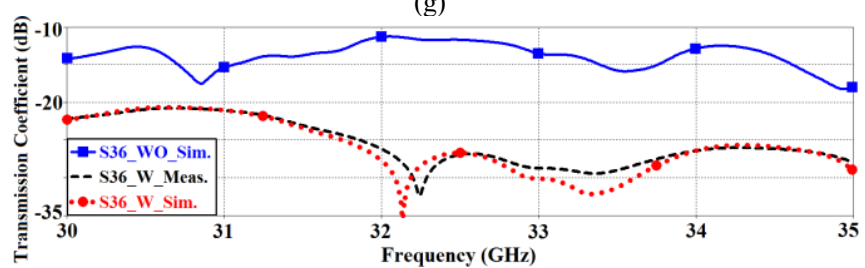

(h)

Fig.2. The simulated (sim.) and measured (meas.) S-parameter performance of the proposed $2 \times 4$ antenna array without (WO) and with (W) decoupling structure. In all cases the array included a defected ground-plane with a dielectric ring under each microstrip-line slot.

A standard measurement set-up was used to measure the array's gain and radiation efficiency. This consisted of a standard horn antenna aligned which was aligned with the antenna under test (AUT). The two antennas were separated from each other by $1 \mathrm{~m}$. The horn antenna and the AUT were connected to the Keysight 8722ES VNA. The loss in the cables is calibrated out from the measurements. The measurement were done in an anechoic chamber. The array's gain was measured via the substitution method with the reference horn antenna by normalizing (or "zeroing") the path loss to $0 \mathrm{~dB}$. 
The reference antenna was then exchanged for the array AUT, and the path gain was remeasured relative to the previously normalized reference path. By simply adding our reference antenna's calibrated gain (in $\mathrm{dBi}$ ) to the path change measurements, we can determine antenna gain in $\mathrm{dBi}$. The radiation efficiency of the array was calculated by taking the ratio of the measured power radiated by the AUT to the input power.

Fig, 3 shows the simulated and measured radiation gain and efficiency of the array over its frequency range. The measured minimum, maximum, and average values of the radiation gain and efficiency with the decoupling structure and defected ground-plane are $11.1 \mathrm{dBi}, 12.9 \mathrm{dBi}, 12 \mathrm{dBi}$, and $80 \%, 90 \%$, $85 \%$, respectively. This is an improvement of $6 \mathrm{dBi}, 7.1 \mathrm{dBi}$, $6.6 \mathrm{dBi}$, and $29 \%, 28 \%, 29 \%$, respectively, compared with no decoupling structure and defected ground-plane. The results of the radiation characteristics are summarized in Table III.

TABLE II. $2 \times 4$ ARRAY ANTENNAS S-PARAMETERS

\begin{tabular}{|c|c|c|}
\hline S-parameters & $\begin{array}{c}\text { Standard array } \\
\text { (Simulation results) }\end{array}$ & $\begin{array}{c}\text { Proposed array } \\
\text { (Measured results) }\end{array}$ \\
\hline $\mathrm{S}_{11}<-10 \mathrm{~dB}$ & $31-34 \mathrm{GHz}(9.23 \%)$ & $30-35 \mathrm{GHz}(15.38 \%)$ \\
\hline Improvement & \multicolumn{2}{|c|}{$2 \mathrm{GHz}(6.15 \%)$} \\
\hline Average $\mathrm{S}_{12}$ & $-14 \mathrm{~dB}$ & $-25 \mathrm{~dB}$ \\
\hline Improvement & \multicolumn{2}{|c|}{$11 \mathrm{~dB}$} \\
\hline Average $\mathrm{S}_{13}$ & $-13 \mathrm{~dB}$ & $-23 \mathrm{~dB}$ \\
\hline Improvement & \multicolumn{2}{|c|}{$10 \mathrm{~dB}$} \\
\hline Average $\mathrm{S}_{14}$ & $-10 \mathrm{~dB}$ & $-23 \mathrm{~dB}$ \\
\hline Improvement & \multicolumn{2}{|c|}{$13 \mathrm{~dB}$} \\
\hline Average $\mathrm{S}_{32}$ & $-14 \mathrm{~dB}$ & $-25 \mathrm{~dB}$ \\
\hline Improvement & \multicolumn{2}{|c|}{$11 \mathrm{~dB}$} \\
\hline Average $\mathrm{S}_{34}$ & $-17 \mathrm{~dB}$ & $-35 \mathrm{~dB}$ \\
\hline Improvement & \multicolumn{2}{|c|}{$18 \mathrm{~dB}$} \\
\hline Average $\mathrm{S}_{35}$ & $-15 \mathrm{~dB}$ & $-30 \mathrm{~dB}$ \\
\hline Improvement & \multicolumn{2}{|c|}{$15 \mathrm{~dB}$} \\
\hline Average $\mathrm{S}_{36}$ & $-13 \mathrm{~dB}$ & $-25 \mathrm{~dB}$ \\
\hline Improvement & \multicolumn{2}{|c|}{$12 \mathrm{~dB}$} \\
\hline
\end{tabular}

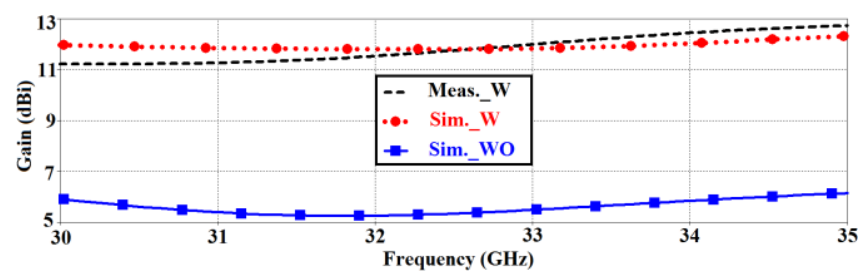

(a)

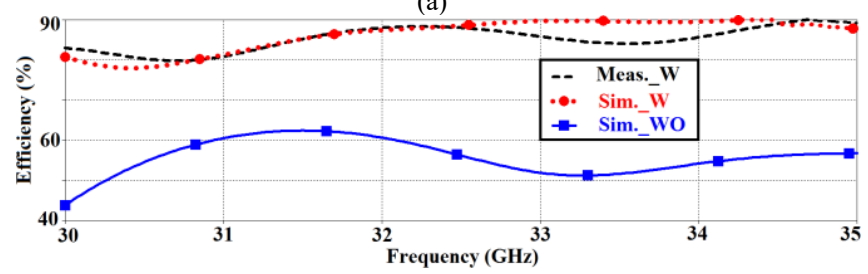

(b)

Fig.3. Radiation characteristics of the proposed antenna array over its operating frequency range without (WO) and with (W). In all cases the array included decoupling structure and defected ground-plane. (a) radiation gain, and (b) radiation efficiency.
TABLE III. RADIATION CHARACTERISTICS OF THE PROPOSED $2 \times 4$ ANTENNA ARRAY.

\begin{tabular}{|c|c|c|c|}
\hline Gain & Minimum & Maximum & Average \\
\hline $\begin{array}{c}\text { Conventional antenna array } \\
\text { (Simulated) }\end{array}$ & $5.1 \mathrm{dBi}$ & $5.8 \mathrm{dBi}$ & $5.4 \mathrm{dBi}$ \\
\hline $\begin{array}{c}\text { Proposed antenna array } \\
\text { (Measured) }\end{array}$ & $11.1 \mathrm{dBi}$ & $12.9 \mathrm{dBi}$ & $12 \mathrm{dBi}$ \\
\hline Improvement & $6 \mathrm{dBi}$ & $7.1 \mathrm{dBi}$ & $6.6 \mathrm{dBi}$ \\
\hline
\end{tabular}

\begin{tabular}{|c|c|c|c|}
\hline Efficiency & Minimum & Maximum & Average \\
\hline $\begin{array}{c}\text { Conventional antenna array } \\
\text { (Simulated) }\end{array}$ & $51 \%$ & $62 \%$ & $56 \%$ \\
\hline $\begin{array}{c}\text { Proposed antenna array } \\
\text { (Measured) }\end{array}$ & $80 \%$ & $90 \%$ & $85 \%$ \\
\hline Improvement & $29 \%$ & $28 \%$ & $29 \%$ \\
\hline
\end{tabular}

\section{COMPARISON WITH STATE-OF-THE-ART}

The proposed $2 \times 4$ antenna array is compared with prior art in terms of the methodology, isolation improvement, number of elements in Table IV. The proposed technique provides high isolation of $18 \mathrm{~dB}$ between the radiation elements bearing in mind it is a larger array than cited in the table. Additionally, the proposed approach is simpler to implement and it does not affect the array's physical dimensions. The proposed array is simple and easy to implement.

TABLE IV. COMPARISON WITH STSTE-OF-THE-ART

\begin{tabular}{|c|c|c|c|c|}
\hline Refs. & Methods & $\begin{array}{c}\text { Max. isolation } \\
\text { improvement }\end{array}$ & $\begin{array}{c}\text { Number of } \\
\text { antennas }\end{array}$ & Simplicity \\
\hline$[11]$ & UC-EBG & $10 \mathrm{~dB}$ & $2(1 \times 2)$ & No \\
\hline$[12]$ & EBG & $4 \mathrm{~dB}$ & $2(1 \times 2)$ & No \\
\hline$[13]$ & $\begin{array}{c}\text { U-shaped } \\
\text { resonator }\end{array}$ & $10 \mathrm{~dB}$ & $2(1 \times 2)$ & No \\
\hline$[14]$ & SCSRR & $10 \mathrm{~dB}$ & $2(1 \times 2)$ & No \\
\hline$[15]$ & $\begin{array}{c}\text { Waveguide } \\
\text { MTM }\end{array}$ & $18 \mathrm{~dB}$ & $2(1 \times 2)$ & No \\
\hline$[16]$ & $\begin{array}{c}\text { Meander line } \\
\text { resonator }\end{array}$ & $10 \mathrm{~dB}$ & $2(1 \times 2)$ & No \\
\hline $\begin{array}{l}\text { This } \\
\text { paper }\end{array}$ & $\begin{array}{c}\text { Decoupling \& } \\
\text { AMC }\end{array}$ & $18 \mathrm{~dB}$ & $8(2 \times 4)$ & Yes \\
\hline
\end{tabular}

\section{CONCLUSION}

The effectiveness of applying decoupling and defected ground-plane techniques to enhance the isolation between radiating elements in an antenna array $(2 \times 4)$ operating in the mmWave band (30-35 GHz) has been practically demonstrated. A crisscrossed decoupling structure comprising slotted microstrip-lines was introduced between the radiation elements and locating in the ground-plane under each vertical slot a dielectric ring. The periodic metallic array essentially acts like an artificial magnetic conductor surfaces for impinging waves, and these waves inside the substrate are fully reflected with a near zero degrees reflection phase. The proposed technique suppresses near-field electromagnetic interactions between the radiation elements as well as propagating surface-waves. The proposed technique does not affect the antenna's dimensions. Additionally, the proposed realization of the antenna and decoupling structure is low cost and simple to implement. This solution is definitely timely and should enhance the 
performance of high-density mmWave MIMO systems for existing $5 \mathrm{G}$ and future wireless systems.

\section{ACKNOWLEDGMENTS}

This work is partially supported by RTI2018-095499-B-C31, Funded by Ministerio de Ciencia, Innovación y Universidades, Gobierno de España (MCIU/AEI/FEDER,UE), and innovation programme under grant agreement H2020-MSCA-ITN-2016 SECRET-722424 and the financial support from the UK Engineering and Physical Sciences Research Council (EPSRC) under grant EP/E022936/1.

\section{REFERENCES}

[1] W. Roh, J. Y. Seol, J. Park et al., "Millimeter-wave beamforming as an enabling technology for $5 \mathrm{G}$ cellular communications: theoretical feasibility and prototype results," IEEE Communications Magazine, vol. 52, no. 2, pp. 106-113, 2014.

[2] Fei Wang, Zhaoyun Duan, Xin Wang, Qing Zhou, and Yubin Gong, "High Isolation Millimeter-Wave Wideband MIMO Antenna for $5 \mathrm{G}$ Communication", International Journal of Antennas and Propagation Volume 2019, Article ID 4283010, 12 pages.

[3] T. S. Rappaport, Y. Xing, G. R. MacCartney, A. F. Molisch, E. Mellios, and J. Zhang, "Overview of Millimeter Wave Communications for FifthGeneration (5G) Wireless Networkswith a focus on Propagation Models," IEEE Transactions on Antennas and Propagation, vol. 65, no. No. 12, pp. 6213-6230, 2017.

[4] M. Alibakhshikenari et al., "A Comprehensive Survey on "Various Decoupling Mechanisms With Focus on Metamaterial and Metasurface Principles Applicable to SAR and MIMO Antenna Systems"," in IEEE Access, vol. 8, pp. 192965-193004, 2020.

[5] M. Alibakhshikenari, et al., "Mutual-Coupling Isolation Using Embedded Metamaterial EM Bandgap Decoupling Slab for Densely Packed Array Antennas", IEEE Access, vol. 7, pp. 5182-51840, April 29, 2019.

[6] M. Alibakhshikenari, et al., "Interaction Between Closely Packed Array Antenna Elements Using Metasurface for Applications Such as MIMO Systems and Synthetic Aperture Radars", Radio Science, Volume53, Issue 11, November 2018, Pages 1368-1381.

[7] M. Alibakhshikenari, et al., "Study on Isolation Improvement Between Closely Packed Patch Antenna Arrays Based on Fractal Metamaterial Electromagnetic Bandgap Structures", IET Microwaves, Antennas \& Propagation, Volume 12, Issue 14, 28 November 2018, p. 2241 - 2247.

[8] M. Alibakhshikenari, et al., "Mutual Coupling Suppression Between Two Closely Placed Microstrip Patches Using EM-Bandgap Metamaterial Fractal Loading", IEEE Access, vol. 7, Page(s): $23606-$ 23614, March 5, 2019.

[9] Z. Y. Li, Z. W. Du, M. Takahashi, K. Saito, and K. Ito, "Reducing mutual coupling of MIMO antennas with parasitic elements for mobile terminals," IEEE Transactions on Antennas and Propagation, vol. 60, no. 2, pp. 473-481, 2012.

[10] J. Liu, K. P. Esselle, S. G. Hay, Z. Sun, and S. Zhong, "A compact superwideband antenna pair with polarization diversity," IEEE Antennas and Wireless Propagation Letters, vol. 12, pp. 1472-1475, 2013.

[11] Farahani, H.S., et al., 'Mutual coupling reduction in patch antenna arrays using a UC-EBG superstrate', IEEE Antennas Wirel. Propag. Lett., Vol. 9, pp. 57-59, 2010.

[12] Yu, A. and X. Zhang: 'A novel method to improve the performance of microstrip antenna arrays using a dumbbell EBG structure,' IEEE Antennas Wireless Propagation Letters, Vol. 2, No. 1, pp.170-172, 2003.

[13] Farsi, S., et al., 'Mutual coupling reduction of planar antenna by using a simple microstrip u-section,' IEEE Ant. and Wirel. Propag. Lett., Vol. 11, pp.1501-1503, 2012.

[14] Suwailam, M. M. B., et al., 'Mutual coupling reduction between microstrip patch antennas using slotted-complementary split-ring resonators,' IEEE Antennas Wireless Propagation Letters, Vol. 9, pp.876-878, 2010.

[15] Qamar, Z. and H. C. Park: 'Compact waveguided metamaterials for suppression of mutual coupling in microstrip array,' Progress in Electromagnetic Research, Vol. 149, pp.183-192, 2014.

[16] Jeet Ghosh, et al., 'Mutual coupling reduction between closely placed microstrip patch antenna using meander line resonator", Progress in Electromag. Research Lett.,Vol. 59, pp.115-122, 2016. 